\title{
Hybrid-Electric Drivetrain: Automakers' Answer to Climate Change
}

\author{
Syed Faraaz Alam ${ }^{1}$, Tejas Adana ${ }^{2}$ and Kanav Khanna ${ }^{3}$ \\ 1, 2, 3: B. Tech (Mechanical Engineering) Student \\ Department of Mechanical Engineering, \\ Shri Govindram Seksaria Institute of Technology and Science Indore, \\ Madhya Pradesh - 452003, India
}

\begin{abstract}
The climate of the globe has been changing for the worst since the first industrial revolution in Europe. One of the major contributors to this global threat has been the automotive industry. Therefore, there is a dire need for the hybrid-electric drivetrain technology to be adopted by the automakers. This paper gives a general overview of hybridelectric drivetrain technology, market trends, some suggestions for making it affordable and increasing the driving range in electric mode. The case study reviews the development of BMW's hybrid technology over the years. In the end, conclusions are drawn as to why hybrid-electric drivetrain technology is a more viable option across the globe.
\end{abstract}

Keywords: Hybrid electric vehicles, hybrid-electric drivetrain, electric vehicle, battery, climate change, hybrid vehicle market trends, BMW edrive, BMW itechnology.

\section{INTRODUCTION}

The advent of the twenty-first century has made humankind realize that fossil fuels won't be available to us forever, their continued usage since discovery has made significant changes in the environment for the worse. This has made different automakers, engineers, and scientists search for alternatives to these fossil fuels, which are ecofriendlier and sustainable. One of the solutions is using hybrid technology in automobiles, specifically hybridelectric drivetrain (HDT).

The term hybrid technology implies the usage of two different fuels to power a vehicle. HDT uses electricity as one of the energy sources, and a gasoline/diesel powered I.C. engine as the other source.

The purpose of this paper is to give an overview of HDT technology and to provide suggestions on how to make it:

1. More affordable.
2. Increase the range in electric mode.

\section{NEED OF HDT}

There are many reasons which call for the need of using HDT in automobiles. Some of these reasons are:

\section{A. AIR POLLUTION}

The first liquid-fuelled internal combustion engine was made in the year 1872, by George Brayton. Then a little more than four decades later, Henry Ford came up with his model $\mathrm{T}$ (gasoline-powered) and changed the world of personal transportation forever. The early engines were more inefficient and polluting when compared to today's engines. The use of petrol and diesel in these engines was the sole cause of this problem.
These fossil-fuel-powered engines release pollutants like carbon monoxide (CO), nitrogen oxides (NOx), hydrocarbons or volatile organic compounds (VOCs), and other particulate matter into the atmosphere as a result of either complete or incomplete combustion of the fuel. These pollutants themselves are a threat to the environment but what is even more dangerous is the complex chemical stew formed as a result when these compounds come in contact with sunlight; ground-level ozone.

Ground-level ozone is a dreadful pollutant. It is a respiratory irritant and may cause premature death in a vulnerable population, like in the case of people having asthma.

Though the engines of today have become more refined, the increased number of vehicles on the roads has deemed these technological advancements insignificant. Therefore, the need for reimagining and changing the power source of automobiles has risen.

\section{B. DEPLETION OF FUEL RESERVES}

It takes millions of years for the formation of fossil fuels, which are a finite resource of energy. The rapid development of the world in the past century has depleted the earth's oil reserves in a haste. The increased consumption of crude oil for power across the globe (especially developing nations with huge population) has increased the problem many folds. The dearth of oil will shoot up the prices and the extraction process will become more tedious, polluting, and expensive.

\section{CLIMATE CHANGE}

The combustion of petrol and diesel in the internal combustion engines produces a range of greenhouse gases, primarily $\mathrm{CO}_{2}$. A variety of human activities, which involve the burning of any carbon-based fuel produce $\mathrm{CO}_{2}$. Hence the elimination of $\mathrm{CO}_{2}$ as a product of combustion of fuels is impossible.

Thus, the only and sure way to reduce $\mathrm{CO}_{2}$ emissions is by decreasing the consumption of petrol and diesel as fuels.

\section{NON-SUSTAINABLE TRANSPORTATION}

\section{GROWTH}

$O F$

Road transportation (automobiles) is a must for any nation. The continued growing demand for automobiles across the globe acts as a multiplier to the problems stated above. The developing nations have a rapid rate of adoption of automobiles, much more than the developed nations. Thus the introduction of HDT in automobiles in these nations can 
mitigate the effects of the aforementioned problems to a great extent.

\section{MAIN COMPONENTS OF HDT}

\section{A. ENGINE}

In a hybrid drivetrain, a combination of two sources of energy is used. In the case of HDT, one of these sources is gasoline while the other is an electric motor. To reduce the $\mathrm{CO}_{2}$ levels produced, we need to reduce the use of petrol, hence an engine of a smaller size should be used. But reducing the size will result in reduced power. To counter this loss, electric motors are used.[2]

\section{B. GENERATOR}

A generator is a device that is used at the time of braking. During braking, the energy from the wheels is used and saved in the battery pack with the help of the generator. This type of braking is known as Regenerative Braking. Some vehicles have a specific generator for both purposes while some have dedicated generators for electricity generation. [2]

\section{BATTERY}

A battery pack is used in a hybrid drive train to store electricity to be used by the electric motor. During braking, the same battery pack is charged through the generator with the help of regenerative braking. [2]

\section{ELECTRONIC CONTROL UNIT(POWER)}

This device sets the perfect harmony between the electric motor and the engine by managing the flow of electricity from the battery to the electric motor and hence controlling the speed of rotation and the amount of torque produced by the motor. During braking, this device is responsible for storing energy in the battery pack. [2]

\section{E. ELECTRIC MOTOR}

The main component of an HDT is its electric motor. An electric motor is a device that uses power from the battery pack and helps the engine in moving the vehicle. In some cases, the electric motor also acts as the generator during braking. In some HDTs, electric motors are installed in combination with the engine, while in some, the electric motors are installed independently in the front wheels. This also gives an extra option of pure electric drive. [2]

\section{WORKING OF HYBRID ELECTRIC DRIVETRAIN}

\section{A. IDLE-OFF}

Idle off is a feature which helps save the fuel. Whenever a vehicle comes to a halt, this feature switches on and turns off the conventional engine, using the battery to operate $\mathrm{AC}$ and other electronics, hence using less fuel. As the vehicle starts moving, the electric assists it in its motion and switches on the engine whenever high power is required (during immediate acceleration for example).[1]

\section{B. REGENERATIVE BRAKING}

Regenerative Braking is one of the best features of an HEV. When a brake is applied by the driver, in a conventional vehicle, the energy will be released as heat from pads in the calliper, whereas in an HEV, this energy is used to charge the batteries.

When the brake is applied, the wheels now rotates the shaft which is connected to the generator, and hence the energy is utilized to charge the batteries. [1]

Note: Regenerative braking does not occur when you slam on the brakes, as at that time the vehicle stops suddenly, and no rotation of wheel occurs.

\section{POWER ASSIST}

Power assist is a feature which is a great help for manufacturers. This feature reduces the demand of power from the Gasoline engine, hence reducing its size, whereas the power loss occurred by reducing the size is compensated by introducing an electric motor which equals the amount of power required in much less space. [1]

\section{ELECTRIC ONLY DRIVE}

Electric-only drive is a feature which helps reduce fuel. During low speeds, this feature turns off the engine and the vehicle is driven only by the electric motor. This helps reduce the fuel usage and then it switches on the engine back only at high speeds at which engine has higher efficiency or low fuel usage. [1]

\section{TYPES OF HYBRID ELECTRIC DRIVETRAINS}

The Hybrid electric drivetrain simply can be defined as the system which relies on two different power sources for motion. The two power sources are mainly the conventional internal combustion engine (petrol or diesel) and the other being the electric propulsion system.

\section{CLASSIFICATIONS OF HDT:}

\section{A. SERIES DRIVETRAIN}

The series drivetrain is the simplest configuration of HDT. Series Hybrids mainly consist of an IC engine, a motor, a generator, and a battery pack. In this configuration, the electric motor is the only means of providing the power to the wheels. The electric motor receives its power from either the generator which is powered by the IC engine or the battery packs. The ECU (Electric Control Unit) then decides the amount of power that is to be given by the battery/generator. The battery pack is charged both by the engine and the generator and also by regenerative braking.

Series hybrids perform their best at stop/start traffic, where most of the IC engines are inefficient. The ECU can opt to power the motor with the battery pack only, saving the engine for situations where it's more efficient. The engine size is typically smaller in this configuration due to the limited power supply demand, and the remaining power requirement is then met by the battery pack. Hence the large battery, a generator, the power electronics, and the motor together contribute to the vehicle's cost, making it more expensive than a parallel hybrid configuration [5] 


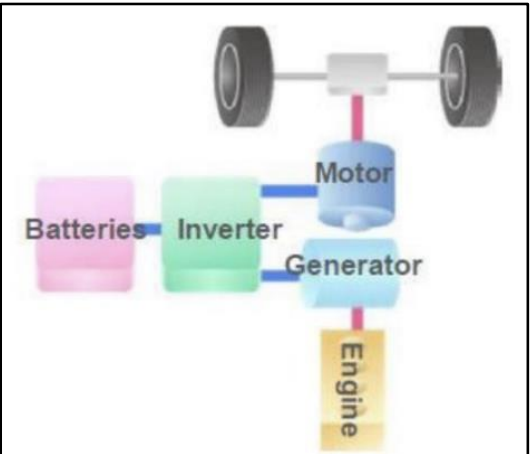

Fig. 1. Series HDT

\section{B. PARALLEL DRIVETRAIN}

In a parallel hybrid drivetrain, the engine and the electric motor work tandemly to supply the power to the wheels. It tends to use a comparatively smaller battery pack which then relies on regenerative braking to gain the charge. As the power demand depletes the motor then acts as a generator for supplement charging, similar to the alternator in conventional cars.

The internal combustion engine and the electric motor are coupled together to a mechanical device which in turn then transfers the power to the wheels, therefore eliminating the inefficiency of converting the mechanical power to electricity and back and also decreasing the cost and volume, increasing the efficiency of the hybrid vehicles in long run [5].

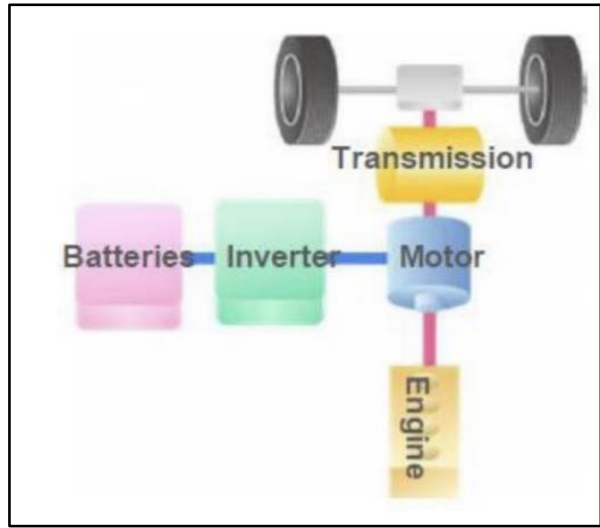

Fig. 2. Parallel HDT

\section{SERIES-PARALLEL DRIVETRAIN}

Series-parallel drivetrain merges the benefits of both the series and parallel drivetrain. By amalgamating both the drivetrains, the engine can power both the wheels simultaneously (as in parallel drivetrain) and can also be effectively discontinued i.e., the power transferred to the wheels only with the electric motor (as in series drivetrain).

The vehicle then can either drive with gas-only and electric-only modes, the engine then operates at optimum efficiency at most of the time. The ECU is tuned so that, at lower speeds, the electric motor kicks in (series drivetrain), and higher speeds, the engine kicks in, and the energy loss is minimized (parallel drivetrain). This system has higher efficiency, minimum energy loss, and low fuel consumption [5].

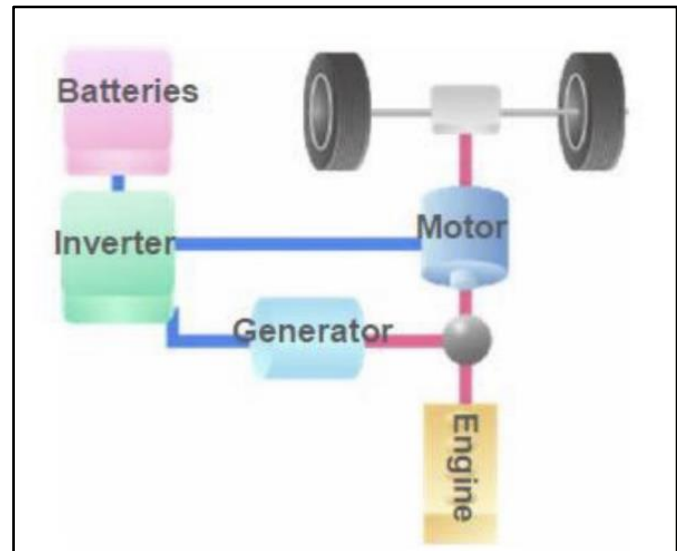

Fig. 3. Series Parallel HDT

Based on the above technology the vehicles can be further classified into [4]:

\section{a. MILD HYBRID}

It is limited to parallel hybrid mode and hence it can be looked up as the combination of an electric motor and an internal combustion engine. The motor alone is not powerful enough to power the wheels at real speed and therefore it requires the assistance of an IC engine. Mild Hybrid vehicles use regenerative braking and ideal start/stop system to recharge as there is no external recharging of the battery. E.g. - Ford Fusion Hybrid, Toyota Prius, Honda Accord Hybrid

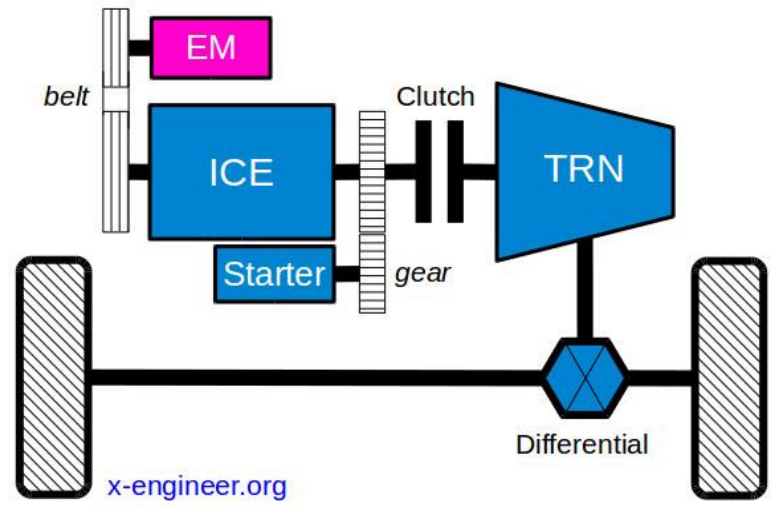

Fig 4. Mild Hybrid Drivetrain Setup

\section{b. FULL HYBRID (FHEV)}

FHEV operates at both the series and parallel configurations. This operation makes the vehicle fuelefficient hybrid vehicle. FHEVs are equipped with an allelectric mode which only comes into action at lower speeds (30 miles) and has a considerably low range (10-15 miles). The combustion engine comes into play as the speed increases and also acts as a generator to recharge the battery packs at the same time. E.g. Ford Fusion Hybrid, Toyota Prius, Honda Accord Hybrid 


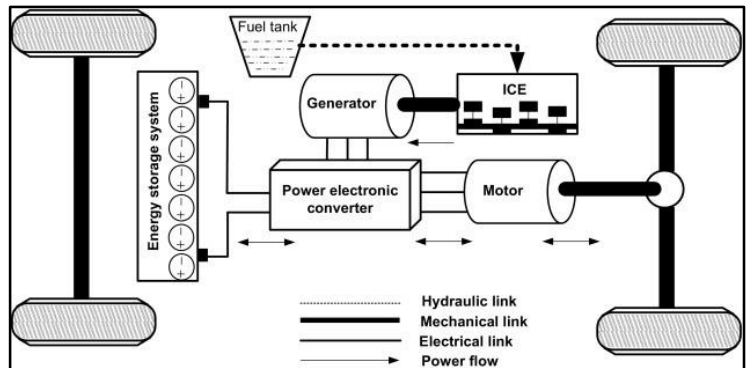

Fig. 5. FHEV Setup

\section{c. PLUG-IN HYBRIDS (PHEV)}

PHEVs, as the name implies uses an external medium to charge the battery packs i.e., a wall adapter or an outdoor supercharger. These have a larger battery capacity which in turn results in the increased electric range at higher speeds as compared to FHEVs. E.g. Audi A2 E-Tron, BMW i8, Ford C-Max Energi, Kia Optima, Porsche Cayenne S, McLaren P1

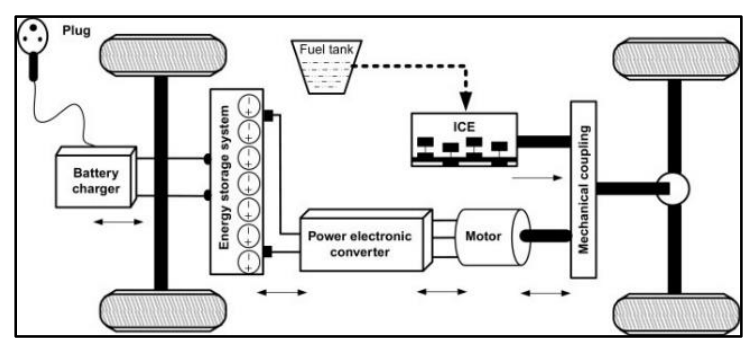

Fig. 6. PHEV Setup

\section{MARKET TRENDS}

The hybrid vehicle market is anticipated to register a CAGR of about $16.35 \%$, during the forecast period (2020 2025).

Some of the major factors driving the growth of the market are growing environmental concerns (owing to rising exhaust emissions), enactment of stringent emissions and fuel economy norms, and increasing government initiatives, in terms of subsidies and benefits for increasing the adoption rate of electric vehicles, are expected to propel the demand for and growth of the high-performance electric vehicles market.

Asia-Pacific is expected to witness a high growth rate during the forecast period. However, incidents such as like China, India lifting and reducing subsidies for the purchase of electric vehicles and US administration rolling back numerous rules related to environment and air pollution may hinder the growth of the market in the region. In India, the government in 2017, lifted subsidies on mild-hybrid vehicles under the FAME scheme (State of Karnataka lost subsidy of INR 75 crores from central government). The cost of hybrid and electric vehicles and lack of charging infrastructure may also hinder the growth rate of the market in emerging economies as cost-sensitive customers are finding conventional IC engine vehicles affordable.

According to the Norwegian Road Federation (NFR), a public road infrastructure administration in Norway, $31.2 \%$ of all the cars sold in 2018 were pure electric. For December
$2018,65.4 \%$ of the total cars registered in Norway were either pure electric or hybrid. Norway plans to end the use of fossil fuels in vehicles by 2025 .

Research and Development in battery technology have increased the battery density and has also brought down the costs. Battery manufacturers are partnering with OEMs and this is driving the growth of hybrid vehicles. [3]

\section{Market Summary CAGR $16.35 \%$}

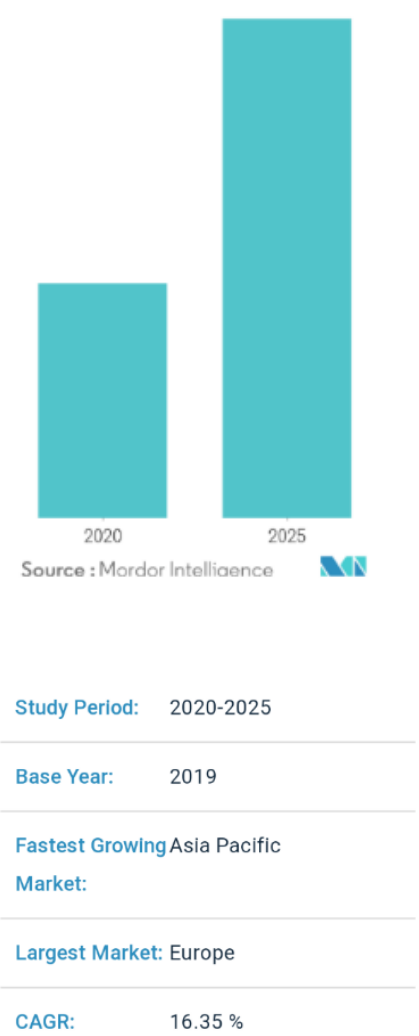

Fig. 7. Market Trends Graph [3]

\section{MAKING HEVS MORE AFFORDABLE}

As the current fuel-economy standards are becoming strict and hence automakers are now compiled to follow these limitations. Hence, they have now become more enthusiastic towards Electric Hybrid Vehicles as the cost of manufacturing them have plummeted. To manufacture HEVs so that they become affordable, these are the suggestions we would like to present:

A. INCREMENTAL

TECHNOLOGICAL

\section{IMPROVEMENTS}

\section{Motors}

The main aspects for the selection of a motor are price performance, lightweight, small size and better efficiency. There are mainly two types of motors used, they are electromagnetic motors and permanent magnet motors. The electromagnetic motor uses certain magnets to produce an electromagnetic field which then converts the electric energy to mechanical energy. Compared to the latter the permanent magnet motor has higher efficiency, less weight and smaller size. But the cost of production increases as it 
uses rare earth material such as dysprosium, which helps in cooling down the motor.

So as the make the motors more affordable an alloy of neodymium, iron and boron co-doped with cerium and cobalt, a less expensive material with properties that are competitive with traditional sintered magnets containing dysprosium. This can then make the permanent magnet motors less expensive and hence result in reducing the cost of HEVs.

\section{Transmission}

The transmission enhances the performance of the hybrid electric drivetrain. By either using a manual transmission or a continuous variable transmission (CVT) the cost of HEV can be decreased. CVT offers the same potentials as a P2 clutch transmission, offering increased fuel economy and also minimizing the emission rates. It offers an infinite number of transmission gear ratios within the limits of the device. This makes the vehicle more economical in terms of both the cost and also more fuelefficient. Also, the usage of hollow shafts instead of solid shafts need to be implemented to make the configuration much economical.

\section{B. ECONOMIES OF SCALE}

The cost of any item gets reduced by a lot when economies of scale come into play, I.e. the cost of any product can be reduced if the production is at a large scale. Automobiles are no exception. Ferrari and Ford are the perfect examples here. The profit margin for selling one Ferrari is the same as selling over nine hundred Fords. The same can be done for hybrid vehicles. If the governments across the globe push for stringent emission norms and raise awareness, people will be inclined to buy hybrid vehicles. The huge demand will certainly cause the automakers to manufacture even more hybrids and economies of scale will start coming into play.

\section{INCREASING THE RANGE IN ELECTRIC MODE}

\section{A. Optimization of ECU (Electronic Control Unit):}

The ECU is the brain of a vehicle. It decides the amount of fuel to be consumed, the amount of power to be delivered, air-fuel ratio makes sure that the motor and the engine work in tandem etc... It can be considered as an equivalent to a processor chip in a mobile phone. Therefore, optimizing the ECU to control the usage of battery is of utmost importance if we would like to increase the range of a hybrid electric vehicle in pure electric drive.

\section{B. Lighter Vehicles}

There is no doubt that a lighter body would require less energy to move when compared to a heavier body. Thus, making a hybrid electric vehicle lighter is a sure way to increase its range in electric mode. This can be accomplished by replacing metals with composite materials in the car, wherever possible. Also, the use of hollow shafts instead of solid shafts will serve this purpose.

\section{CASE STUDY}

BMW gave the world glimpses of what it would look like when they enter into the hybrid electric car market back in 2009. This was a new domain, one which the automaker had never entered. The company had some challenges which they needed to overcome:

1. A drivetrain which delivers powers that matches BMW's standards.

2. A top-performing hybrid electric car which can be brought into mass production.

3. A battery management system which allows the driver to enjoy a powerful drive even in electric mode for a long-range.

BMW's answers to these challenges are:

A. BMW i DRIVE TECHNOLOGY:

The BMW $\mathbf{i}$ is a sub-brand of BMW founded in 2011 to design and manufacture plug-in electric vehicles. The company's initial plans call for the release of two vehicles; the i3 all-electric car and the i8 plug-in hybrid. Concept versions of both these vehicles were shown at the 2009 Frankfurt Motor Show.

Series production of the BMW i3 destined for retail customers began in September 2013, and the European market launch took place in November 2013 with the first retail deliveries in Germany. The BMW i8 was launched in Germany in June 2014. The United States, Norway, Germany, and the UK are the main markets for both models.

In February 2016, BMW announced the introduction of the "iPerformance" model designation, which is being given to all BMW plug-in hybrid vehicles from July 2016. The aim is to provide a visible indicator of the transfer of technology from BMW i to the BMW core brand [7].

\section{B. Project $i$}

BMW's "Project $\mathrm{i}$ " is a program created to develop lightweight eco-friendly urban electric car concepts designed to address the mobility and sustainability needs for people who live in megacities. According to BMW, "Project $i^{\prime}$ has three phases. The Mini E demonstration was the first phase of this project, and it was followed by a similar field testing that began in January 2012 with the BMW ActiveE all-electric vehicle. The ActiveE was based on the BMW 1 Series Coupe and built considering the lessons learned from the Mini E trial. The last phase of "Project i" was the development of the i3 and i8 electric cars.

In February 2011, BMW announced a new sub-brand, BMW i, to market the vehicles produced under Project $i$. BMW i vehicles are to be sold separately from BMW or Mini. The first two production models are the BEV (battery electric) Mega City Vehicle, now called BMW i3, and a plug-in hybrid called BMW i8, which is the production version of the Vision Efficient Dynamics concept unveiled at the 2009 Frankfurt Motor Show and has an all-electric range of 50 kilometres $(31 \mathrm{mi})$ 
Production of both plug-in electric cars was scheduled to start in Leipzig in 2013.[7]

\section{BMW i8:}

The BMW i8 plug-in hybrid is the production version of the BMW Vision Efficient Dynamics concept unveiled at the 2009 Frankfurt Motor Show and has an all-electric range of 35 kilometres $(22 \mathrm{mi}$ ). Production of both plug-in electric cars is scheduled to start in Leipzig in 2013. ${ }^{[3]}$ Powering the front wheels will be an electric motor $(131 \mathrm{hp})$, while the rear wheels will make use of a 1.5-litre 3-cylinder gasoline engine $(231 \mathrm{hp})$. Zero to $60 \mathrm{mph}$ sprint timings are estimated to be less than 4.5 seconds using both power sources. The positioning of the motor and engine over the axles also makes it benefit from a 50/50 weight distribution.[7]

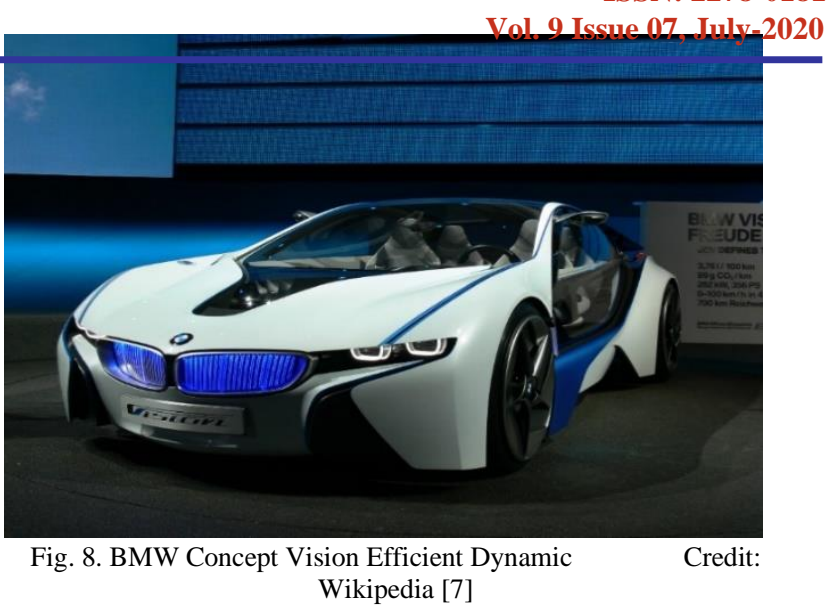

TABLE I. BMW i8 EPA RATINGS [7]:

\begin{tabular}{|c|c|c|c|c|}
\hline \multicolumn{5}{|c|}{ BMW i8 EPA ratings } \\
\hline Model & $\begin{array}{c}\text { Year } \\
\text { Model }\end{array}$ & $\begin{array}{c}\text { Fuel/EV } \\
\text { range }\end{array}$ & Combined & City/Highway \\
\hline \multirow{2}{*}{ BMW i8 } & \multirow{2}{*}{$\begin{array}{l}2014 \\
2015 \\
2016\end{array}$} & $\begin{array}{c}\text { Electricity } \\
\text { Only } \\
15 \mathrm{mi}(24 \mathrm{~km})\end{array}$ & $\begin{array}{c}76 \mathrm{mpg}-\mathrm{e} \\
(43 \mathrm{~kW}- \\
\mathrm{hrs} / 100 \mathrm{mi})\end{array}$ & - \\
\hline & & $\begin{array}{c}\text { Gasoline Only } \\
315 \mathrm{mi} \\
(507 \mathrm{~km})\end{array}$ & $28 \mathrm{mpg}$ & $28 \mathrm{mpg} / 29 \mathrm{mpg}$ \\
\hline
\end{tabular}

TABLE II. BMW i8 ENGINE SPECIFICATIONS [7]:

\begin{tabular}{|c|c|c|c|c|}
\hline Model & Year & Type & Power & Torque \\
\hline \multirow{4}{*}{ i8 } & & & & \\
& \multirow{4}{*}{$\mathbf{2 0 1 4 - 2 0 1 8}$} & $\begin{array}{c}1,499 \mathrm{cc}(91.5 \mathrm{cu} \text { in }) \mathrm{I} 3 \\
\text { turbo B38A15T0 }\end{array}$ & $\begin{array}{c}231 \mathrm{PS}(170 \mathrm{~kW} ; 228 \mathrm{hp}) \text { at } 5800 \\
\mathrm{rpm}\end{array}$ & $320 \mathrm{~N} \cdot \mathrm{m}(236 \mathrm{lb}-\mathrm{ft})$ at 3700 \\
& & & $131 \mathrm{PS}(96 \mathrm{~kW} ; 129 \mathrm{hp})$ & $250 \mathrm{~N} \cdot \mathrm{m}(184 \mathrm{lb}-\mathrm{ft})$ at $0 \mathrm{rpm}$ \\
\cline { 3 - 5 } & & hybrid synchronous motor & $362 \mathrm{PS}(266 \mathrm{~kW} ; 357 \mathrm{hp})$ & $570 \mathrm{~N} \cdot \mathrm{m}(420 \mathrm{lb} \cdot \mathrm{ft})$ at $0 \mathrm{rpm}$ \\
\cline { 3 - 5 }
\end{tabular}

\section{BMW e-DRIVE TECHNOLOGY:}

The BMW e-drive is a configuration of electrical motor, lithium-ion high-performance battery and intelligent energy management system. BMW e-drive is an intelligent system in which both the electric motor and the IC engine are so combined to reduce the fuel consumption and emissions without compromising the performance of the vehicle. It offers the option of driving on electric power alone and therefore with zero local emissions - yet at the same time reveals the ability to cover long distances when the twodrive systems team-up [6].

\section{E. BMW 740e:}

It is one of the latest additions to the BMW e-drive line up, along with 330e, 745e, 745Le x-Drive, X5 x-Drive45e and $\mathrm{X} 3 \mathrm{x}$-Drive30e being the others to use this configuration.

The power train used in BMW 740e is of a four-cylinder petrol engine with BMW Twin-Power Turbo technology and an electric motor integrated into the eight-speed Steptronic transmission to generate a system output of $240 \mathrm{~kW} / 326 \mathrm{HP}$.

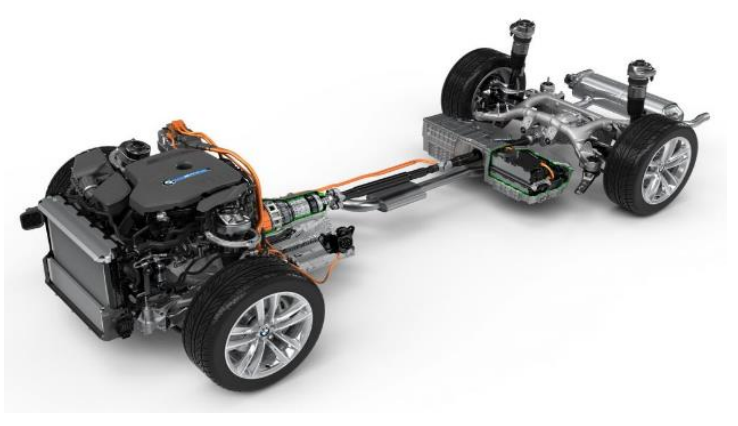

Fig. 9. BMW 740e plug-in hybrid electric vehicle (PHEV) powertrain and drivetrain Credit: BMW

It is a concentric parallel hybrid electric vehicle I.e. both the ICE and the electric motor can power the same axel (front, rear or both). It has an intelligent all-wheel-drive system which can distribute the combined power to the rear and the front wheels as required. 
TABLE III. THE FUEL EFFICIENCY FIGURES AND ELECTRIC RANGE:

\begin{tabular}{|c|c|c|}
\hline & 740e iPerformance & 740Le iPerformance \\
\hline Fuel consumption [1/100 km] & \multicolumn{2}{|c|}{$2.0-2.2$} \\
\hline Mileage [mpg] & \multicolumn{2}{|c|}{$141.2-128.4$} \\
\hline $\mathrm{CO}_{2}$ emissions $[\mathrm{g} / \mathrm{km}]$ & $45-50$ & $45-51$ \\
\hline Electric range $[\mathrm{km}]$ & \multicolumn{2}{|c|}{$\begin{array}{ll}1 \\
44-48 \\
\end{array}$} \\
\hline
\end{tabular}

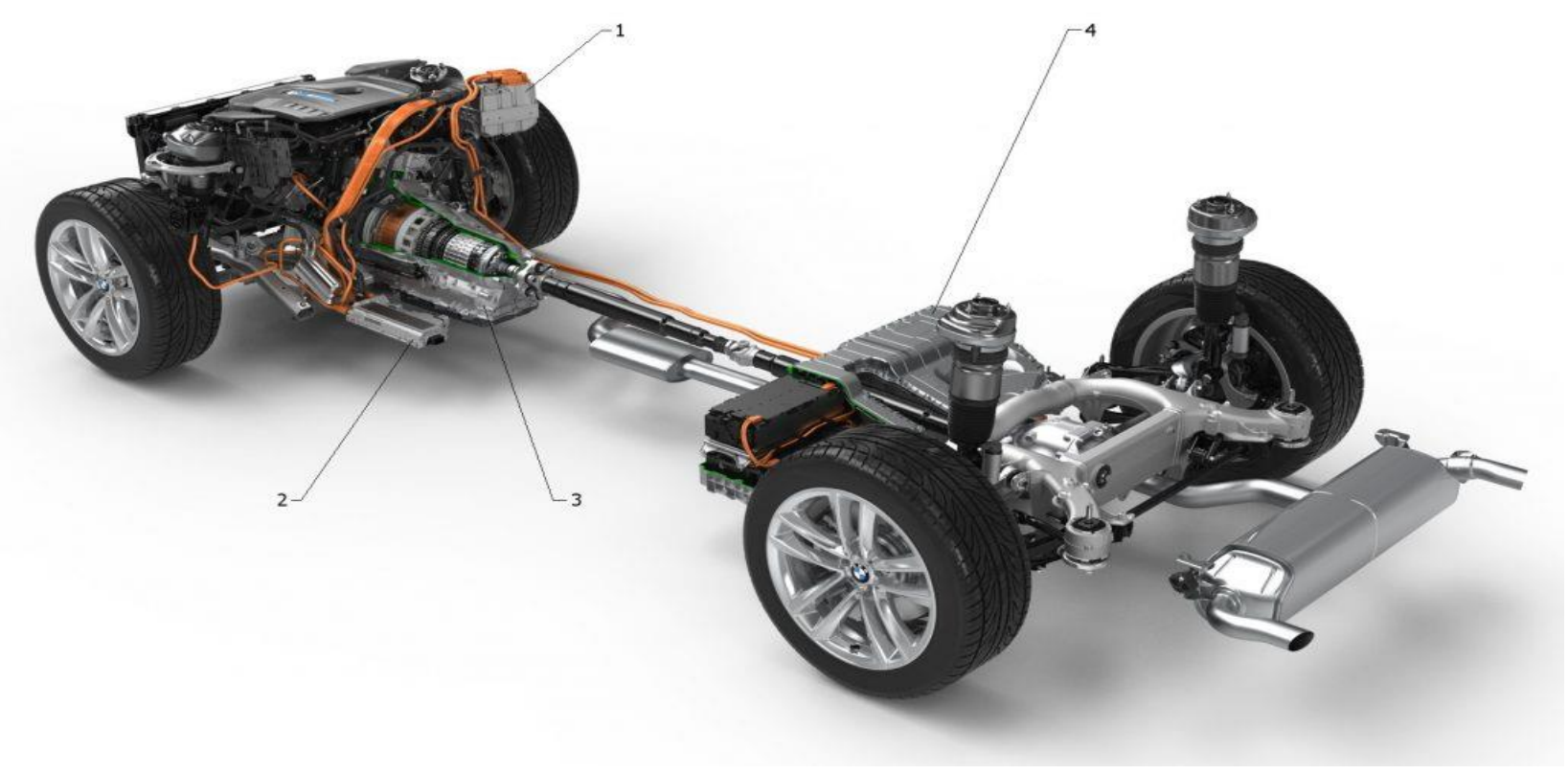

Fig. 10. BMW 740e plug-in hybrid electric vehicle (PHEV) main components Credit: BMW [6]

The drivetrain consists of a 2.0-litre gasoline engine developing a maximum output of $190 \mathrm{~kW} / 258 \mathrm{HP}$ mated along with a ZF's integrated motor- generator ZF8HP hybrid automatic gearbox where:

1. power electronics module

2. high voltage battery charger controller

3. ZF8HP hybrid automatic transmission

4. high voltage battery

The hybrid transmission (ZF8HP) is provided by ZF (Germany). Based on the principle of a permanently excited synchronous motor, the electric drive system stands out with its linear power delivery up into the higher reaches of the speed range and its exceptionally high level of efficiency. Its maximum output is $83 \mathrm{~kW} / 113 \mathrm{HP}$. And, as is characteristic for electric drive systems, it serves up its peak torque of 250 $\mathrm{Nm}$ (184 lb-ft) from the word go. The electric motor is fully integrated into the car's eight-speed Steptronic transmission. This ensures that pure-electric driving, the dynamics-enhancing electric boost function and the recuperation of braking energy all happen extremely efficiently. The integration of the electric motor also means the transmission does not require a torque converter (enabling a reduction in weight), while the hybrid module takes over the function of the starter element. The electric motor also acts as a generator depending upon the mode, which is selected by the user, either by recuperating energy on the overrun and under braking or by efficiently raising the engine's load points. It then feeds the energy it generates into the high-voltage battery.

The system uses a lithium-ion battery and has a gross capacity of $9.2 \mathrm{kWh}$. It in total consists of 96 cells arranged in six modules and has its cooling system integrated into the climate control system for the interior. It can be topped up with any domestic power socket in about four hours [6]. 


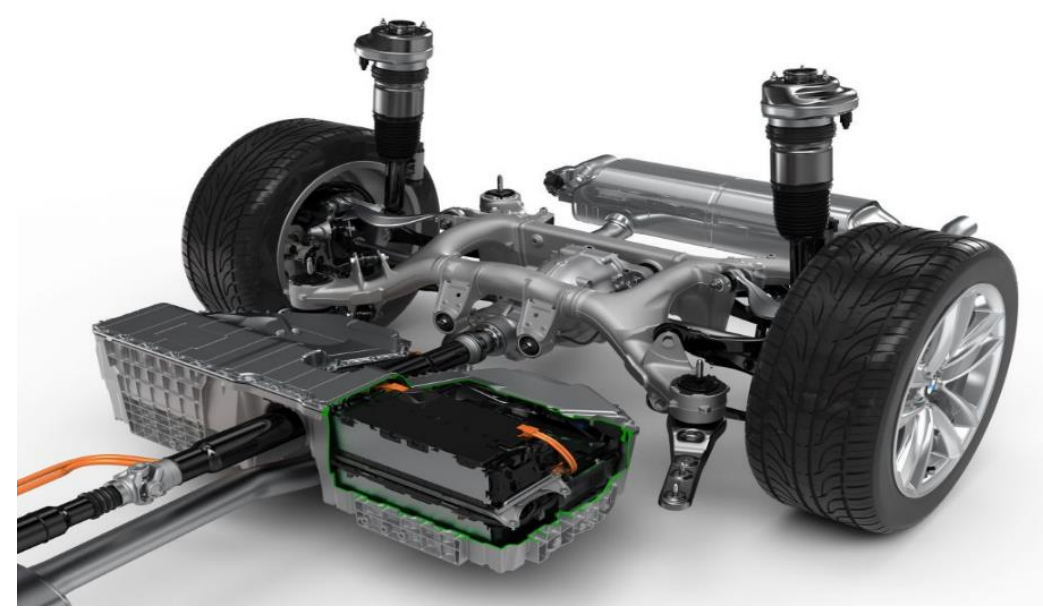

Fig. 11. BMW 740e iPerformance plug-in hybrid electric vehicle (PHEV) high voltage battery Credit: BMW [6]

TABLE IV. THE POWERTRAIN CAN BE OPERATED IN FIVE MODES. THESE ARE SUMMARIZED IN THE TABLE BELOW.

\begin{tabular}{|l|l|l|l|l|}
\hline \multicolumn{1}{|c|}{ Powertrain mode } & \multicolumn{1}{c|}{ ICE state } & \multicolumn{1}{c|}{ EM state } & \multicolumn{1}{c|}{ K0 clutch state } & IAE clutch state \\
\hline $\begin{array}{l}\text { Electric Drive (EV } \\
\text { mode) }\end{array}$ & Off & $\begin{array}{l}\text { Motor mode (positive } \\
\text { torque) }\end{array}$ & open & Closed \\
\hline Parallel (torque-assist) & On (positive torque) & $\begin{array}{l}\text { Motor mode (positive } \\
\text { torque) }\end{array}$ & closed & Closed \\
\hline Regeneration & $\begin{array}{l}\text { Off / On (negative } \\
\text { torque) }\end{array}$ & $\begin{array}{l}\text { Generator mode } \\
\text { (negative torque) }\end{array}$ & open / closed & Closed \\
\hline Hold (charge) & On (positive torque) & $\begin{array}{l}\text { Generator mode } \\
\text { (negative torque) }\end{array}$ & closed & Closed \\
\hline Coasting & Off & Off & open & open / closed \\
\hline
\end{tabular}

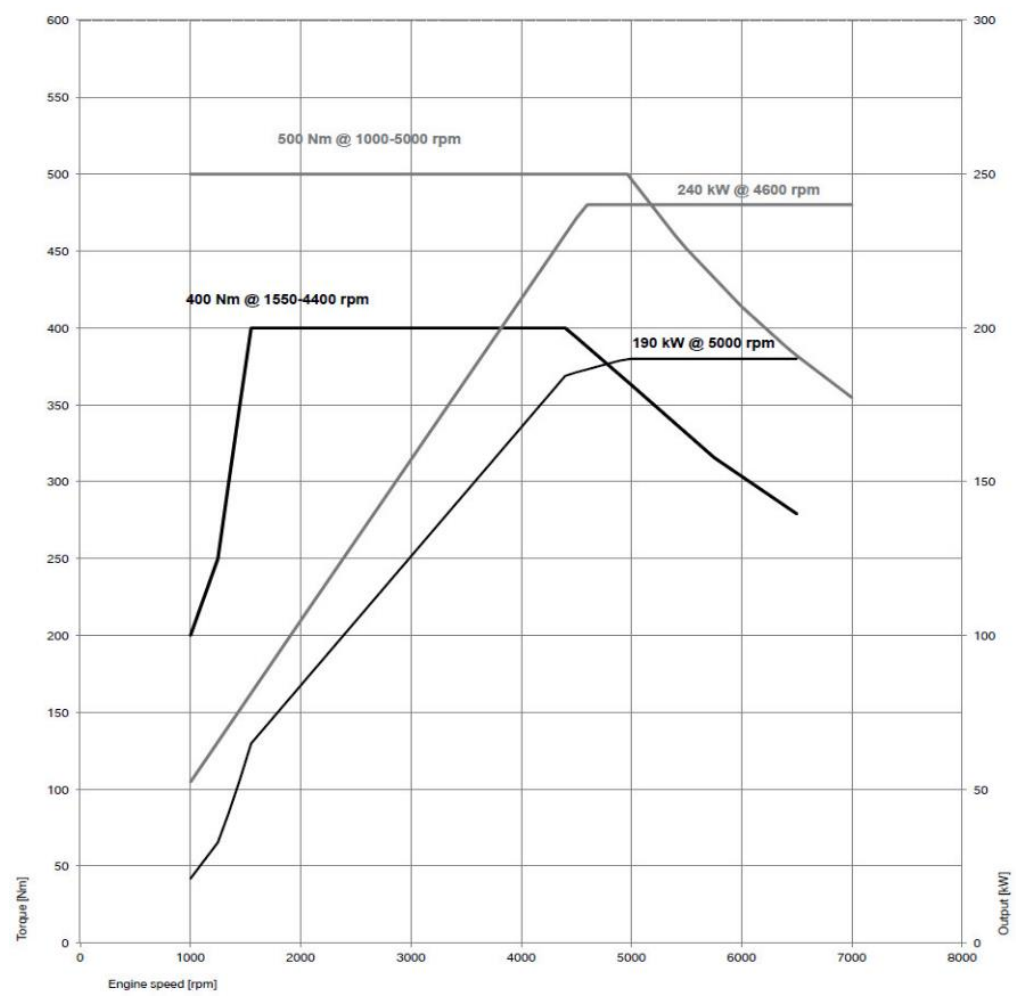

Fig. 12. BMW 740e plug-in hybrid electric vehicle (PHEV) powertrain output Credit: BMW 


\section{CONCLUSION}

In today's world, where every government is pushing towards greener technology, electric and hybrid electric vehicles are becoming a necessity. Hybrid vehicles bring the best of the two technologies (internal combustion and electric drive) together, adding their advantages and compensating for their shortcomings. Even though hybrid vehicles have a larger carbon footprint than the electric vehicles in the developed nations, it is almost the same in the developing countries. Even more, the electric vehicles have a shorter driving range and longer charging (re-fuelling) time. These reasons are enough to motivate countries and automakers to adopt hybrid-electric drivetrain technology for the foreseeable future.

\section{REFERENCES}

[1] Union of Concerned Scientist (ucsusa.org) - How Do Hybrid Cars and Trucks Work?

[2] Alternative Fuel Data Centre, U.S. Department of Energy (afdc.energy.gov) - How Do Hybrid Electric Cars Work?

[3] Hybrid vehicle market - analysis of growth, trends, and forecast (2020 - 2025) (https://www.mordorintelligence.com/industryreports/hybrid-vehicle-market)

[4] Types of Hybrid Vehicle - Stuart Greenwood (https://www.aathornton.com/hybrid-vehicles-simple-guide/)

[5] Types of Hybrid Electric Drivetrain (http://autocaat.org/Technologies/Hybrid_and_Battery_Electric _Vehicles/HEV_Types/)

[6] BMW's iPerformance plug-in hybrid electric vehicle (PHEV) powertrain architecture (https://x-engineer.org/automotiveengineering/vehicle/hybrid/bmw-iperformance-plug-in-hybridelectric-vehicle-phev-powertrain-architecture/)

[7] BMW i8 - Wikipedia (https://en.wikipedia.org/wiki/BMW_i8)

[8] Karan C Prajapati, Ravi Patel, Rachit Sagar - Hybrid Vehicle: A Study on Technology - IJERT, Vol. 3, Issue 12, December 2014. 